\title{
Access and barriers to health care delivery in Arab countries: a review
}

\author{
N.M. Kronfol ${ }^{1}$
}

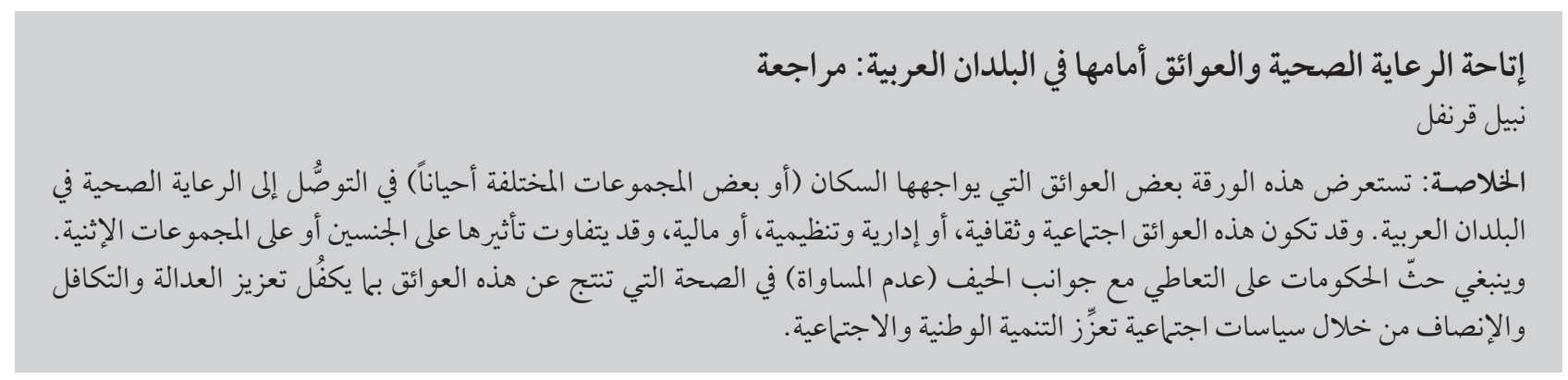

ABSTRACT This paper reviews some of the main obstacles encountered by the population (or rather by different social groups) in accessing health services in Arab countries. These obstacles can be social and cultural, administrative and organizational or financial and may impact on gender and ethnic groups to different degrees. Governments are urged to address the health inequalities that result from these obstacles and promote equity, solidarity and fairness through social policies that enhance social and national development.

\section{Accès et obstacles aux prestations de soins de santé dans les pays arabes : revue}

RÉSUMÉ Le présent article examine certains des principaux obstacles rencontrés par la population (ou plutôt différents groupes sociaux) pour accéder aux services de santé dans les pays arabes. Ces obstacles peuvent être d'ordre social, culturel, administratif, organisationnel ou financier et avoir un impact sur la population en fonction du sexe et de l'ethnie à des degrés divers. Les gouvernements sont instamment priés de s'attaquer aux inégalités en santé engendrées par ces obstacles et de promouvoir l'équité, la solidarité et la justice au moyen de politiques sociales qui renforcent le développement social et national. 


\section{Introduction}

The access to and utilization of health services remain serious concerns to the health care systems of the Arab countries. Despite major improvements that have occurred over the past 3 decades, several subsets of the population in most countries continue to face difficulties utilizing the range of health services available. It is feared that these difficulties may increase with the current trend towards a greater degree of cost-sharing and co-payment for health care. Ensuring equitable access to high-quality health care constitutes a key challenge for health systems throughout the Arab world. Despite differences in health system size, structure and financing, evidence suggests that across the region particular sections of the population are disproportionately affected by barriers to accessing health care [1]. This paper, the fourth in series of reviews about health services in the Arab region [2-5], will attempt to identify and analyse barriers to accessing and utilization of health care, particularly for vulnerable people.

\section{The health basket}

The term "health benefit basket" has been defined by Rodrigues-Sanz et al. as the totality of services, activities and goods reimbursed or directly provided by a public health care programme. The decision criteria for inclusion are often based on need, appropriateness, effectiveness and cost-effectiveness [6].

Public health care programmes in the Arab countries provide comprehensive coverage of all levels of care, including prevention, ambulatory care and inpatient services. These services are normally either completely free of charge or received at a nominal fee. Some of the main gaps in coverage include non-prescription drugs, dental care, cosmetic surgery and smoking cessation. Some treatments are constrained or prohibited in certain countries based on moral and bioethical grounds, such as fertility treatments and abortion. As a consequence, it is frequently the case that patients choose to go abroad to receive such treatments. In the case of fertility treatments, in some cases, women travel to countries where "donor anonymity is guaranteed is guaranteed for sperm and egg donations" [7]. However, formal legal entitlements do not necessarily mean that barriers do not exist. Regulations on health baskets frequently interact with cost-sharing rules, imposing limits on the range of services that are actually accessible. The enforcement of legal regulations in many cases is lacking.

\section{Common exclusions from the health basket}

\section{Dental care}

An area of health care with incomplete coverage in the Arab region is the provision of dental services. In a few countries there is wide coverage offered in the public clinics. However, dental services tend to be limited to diagnosis, filling and extraction. Dental prostheses are minimally covered even in the wealthier countries. Dental supplies may be limited, pushing clients to seek care in the private sector. Coverage favours younger people.

The proportion of dentists to the general population has become adequate only recently in most countries. However, these dentists practise predominantly in the private sector. When they do have sessions in the public clinics, it is believed that this dual employment facilitates a shift of patients to their private office. Even in countries that have adopted social health insurance, dental care has not been covered as yet, for example in Lebanon.

The exclusion of dental care from the health basket is not limited to the countries of the region. Several studies from Europe have produced evidence that the use of dental services is lower among groups of lower socioeconomic status [8-10]. Moreover, the concentration of dentists in the cities of the Arab region severely limits access in rural areas [11]. An expansion of coverage of dental health services is needed to improve oral health.

\section{Mental health}

Similar problems also apply to mental health services. In many cases these are covered only to a certain extent and there are non-financial constraints that limit access. Long waiting lists encourage patients to seek care in the private sector. Counselling and psychotherapy services are frequently not covered in the public clinics. There is a tendency to prioritize younger adults with mild disorders, little co-morbidity and high educational status, while mentally retarded people, people with severe mental health problems, those with severe somatic co-morbidities, the elderly and people of low educational status tend to be disadvantaged. Cost sharing can also be substantial for a range of services that mental health patients would greatly benefit from, such as individual psychotherapy in ambulatory care.

\section{Geographical barriers to access to health services}

Three aspects of geographical barriers to access to health care services can be identified: transport, regional variations and rural-urban inequalities. Specific policy measures need to be taken to alleviate costs, help reduce travel hurdles or to ensure the proximity of facilities.

\section{Transport}

Transportation is an important issue when people are dependent on public transport to access health care. This is particularly the case in rural areas. Moreover, people with functional 
impairments need particular help to reach health care services [12]. In some countries of the Arab region, there is a concern about the safety, cost of transportation and ease of boarding public buses. Older people are particularly disadvantaged in this respect $[13,14]$.

Distance has been shown to limit access to health care [15]. In many Arab countries, the need to wait for a male guardian to arrange for transportation presents an obstacle for care, especially if the public clinics have early closing hours $[15,16]$. The impact of distance on utilization of preventive services such as screening appears to be greater than on curative treatments, especially where follow-up treatments are required $[15,17]$. It should be remembered that car ownership is limited in the more disadvantaged groups.

Methods and availability of transportation of course vary within and between Arab countries. One study interviewed clients attending primary health care centres across Lebanon [18]. Close to half the respondents had come to the clinic on foot. In the regions when clients did not walk, they came to the clinic predominantly through private transport. The overall usage of public transport was a mere 5\%, while private transport was used by $30 \%$ and taxi by another $17 \%$. Three-quarters of the clients reached the clinic within 15 minutes and 95\% within 30 minutes. Most of the clients who took longer to reach the clinic were in urban areas where traffic jams may have been responsible for the delay for those who were accessing the clinic by car, rather than by walking. These figures indicate that transportation and distance to the clinic did not appear to present access difficulties in Lebanon [18].

Disabled persons have very specific needs in terms of accessibility of health care facilities and access to information [16]. For instance, in some cases it is necessary to guarantee that physical facilities are easily accessible for wheelchair users or that leaflets or other sources of information are provided in appropriate formats for those with visual impairment.

\section{Regional variations and rural- urban disparities}

Rural-urban inequalities in access to health care are an important issue in several countries of the Arab region, particularly given that rural areas often experience a more fragile economic and demographic situation, with more people at risk of poverty and social exclusion [19]. Health indicators (infant morality rate, maternal mortality ratio) vary significantly between areas, even within a small country such as Lebanon [20]. In addition, it has been observed that health beliefs of rural peoples can delay early consultation/contact with health services and late appearance [21].

Ibnouf et al. studied the utilization of routine antenatal health care services in Sudan. The study reported that utilization was approximately 5 times higher and provision of tetanus toxoid vaccination was 3.7 times higher among urban women as compared with women in rural areas. Mothers' education showed a nearly significant positive relationship both with the use of routine antenatal health care service [22].

\section{Cultural barriers to access}

Cultural barriers to access and utilization include gender, ethnicity and race, nationality and religion.

\section{Gender}

Differences in rates of utilization of services (possible due to reproductive health) according to gender are well recognized as one of the predisposing factors for utilization [23]. Gender affects both the patient and the provider and is related to socioeconomic status, cultural factors and education. Research suggests that providers' inability to respond to health problems in a sensitive manner can affect service use [24]. In general women prefer women physicians, especially concerning reproductive health matters [25]. Concepts such as gender-based or gender-sensitive care are being integrated into health strategies in the region. Specific genderrelated issues in the Arab region include: improving women's access to health care, education and literacy for girls and women, employment and social protection for women and female genital mutilation.

Although women are major health care users as well as providers, they are under-represented in decision-making in health care [26]. However, there is general agreement among women's organizations in more progressive countries, such as Tunisia and Lebanon, that "gender sensitive health care should be available, accessible, affordable, appropriate and acceptable", much as is the case in the European community [27].

In addition to issues related to access, rights for care and differentials in decision-making and community leadership, a study demonstrated that women experience indeed different symptoms and care patterns than men [28]. Noureddine et al. from Lebanon have demonstrated that the signs and symptoms of acute coronary syndromes differ between men and women. This study from the American University of Beirut explored differences between Lebanese men and women in cognitive, emotional and behavioural responses to signs and symptoms of acute coronary syndromes [28]. The study concluded that factors related to promptness in seeking care for acute coronary syndromes differ between Lebanese men and women, similar findings to a study from the University of Toronto [29].

A study of gender differences in health care utilization and outcome of respiratory tuberculosis has been reported from Alexandria, Egypt. The pattern of tuberculosis symptoms was similar for both sexes. Women started treatment earlier than men, but 
women had significantly lower scores in knowledge, beliefs and attitudes about tuberculosis than men. Compliance was unsatisfactory for both sexes [30]. Another study from the Syrian Arab Republic found that delay in the diagnosis of tuberculosis was significantly longer among males. Differences between males and females were also noted in relation to the place they usually seek care. Although women reported more barriers to seeking care, compliance with treatment tended to be higher and the treatment success rate was significantly higher among females than males [31].

\section{Ethnicity and race}

Ethnic minorities refer to groups of people with a common origin, common cultural and linguistic features (e.g. religion, norms, and language) and some kind of social organization or a sense of belonging together (ethnic identity).

A large body of literature suggests that those from vulnerable groups, including older, socioeconomically disadvantaged and people from ethic minorities may be viewed as less suitable candidates than those from more advantaged groups $[32,33]$ This is related to the professionals' views on suitability of people for treatment. Racism in public places and public transport may pose an important barrier for some ethnic groups. Specific patterns of help-seeking behaviour have been identified among people with minority ethnic backgrounds in the region. For example, it has been reported that Arab Israeli women tend to rely more on emergency services than do Jewish Israeli women [34]. Language barriers have also been shown to limit access to health care among ethnic minorities [35]. Perceptions of cultural sensitivity of services have been reported as an important influence on both entering into the health care system and maintaining contact [36]. Barriers to help-seeking include perceptions of language difficulties, lack of awareness about beliefs and values and lack of translation facilities
[37]. Racism in public places and public transport may pose an important barrier for some ethnic groups [37]. Ensuring adequate communication is one of the responsibilities of health professionals. Recruitment of health care staff from ethnic minority communities eases communication problems and enhances accessibility [36]. However, there are mixed views about "ethnic matching" as a means of promoting access [37].

Preliminary analysis of the Bedouin Health Project at the American University of Beirut appeared to show a high level of acceptance of modern clinics and medical practices (most births take place in hospitals, for example), coupled with a decrease in the use of traditional medicine. However, seeking medical advice or intervention appeared to be hindered and influenced by factors such as financial barriers and discrimination. Although this did not prohibit the women from seeking health care, it highly compromised the quality of these services; medical history was only partially collected and the women were not given the chance to communicate their concerns [38].

Little is known about the effect of race on health care access in Arab countries. There is a substantial subset of the population with African or Asian origins and features who have moved to the Arab countries as a result of migration, pilgrimage (hajj), occupation and slavery in the past. Research is needed to establish whether they suffer racial discrimination that creates differences in patterns of utilization or barriers to medical services for these subgroups.

\section{Nationality}

Barriers related to nationality are perhaps most evident in the Gulf countries, where some facilities are restricted to the nationals of the country and others reserved for non-nationals or expatriates. In general, facilities for nationals receive more support from government. It must be stated, however, that the facilities for expatriates are also of a good standard.
This dichotomy has been raised many times in discussions and debates $[\mathrm{N}$. Kronfol. Personal communication with the Minister of Health of United Arab Emirates, 1992]. It seems to relate to sociocultural factors rather than medical issues. For the governments of the region, the medical services provided to some expatriates are superior to those they could receive in their country of origin. However, the differentiation in care settings raises issues of segregation and differentials between patients according to nationality.

Different nationalities have been shown to exhibit different patterns of utilization of medical services in the region. In a random telephone survey in Israel of 9352 persons carried out in 2007 Arabs more often reported visiting a family physician than a specialist compared with Jews. The authors conclude that a different pattern of utilization of health care services exists that is not explained by differences in socioeconomic levels [39]. A study from Kuwait revealed differences in access to primary health centres among different nationals. Compared with Kuwaiti nationals, $92 \%$ of whom were registered at the health centres, only $62 \%$ of the Arabs and $39 \%$ of the Asians were registered. Nationality was the most important reason for lack of registration [40].

\section{Religion}

Religion plays an important role in health in the Arab countries. Although the boundaries between religion and other sociocultural factors are not easily discernable, health, as a mirror of society, is influenced by religion [41]. Perhaps the greatest influence of religion lies in issues related to reproductive health such as abortion. A comprehensive paper by Hessini provides an overview of legal, religious, medical and social factors that serve to support or hinder women's access to safe abortion services in the 21 predominantly Muslim countries in the Middle East and North Africa, where 1 in 10 pregnancies ends in abortion [42]. 
Religion has an important influence on certain specific health practices such as male and female circumcision, the practice of medicine and litigation, the belief in fate and destiny and other social determinants of health [43].

\section{Health literacy, voice and health beliefs}

The World Health Organization Health Promotion Glossary defines health literacy as follows: "Health literacy represents the cognitive and social skills, which determine the motivation and ability of individuals to gain access to, understand and use information in ways which promote and maintain good health". "Inequitable disparities in healthcare utilization can exist even where health services are accessible because patients' expectations and other non-health related aspects also affect access and utilization of services" [44]. Education has been known to be another predisposing factor of health care utilization, especially the education of the mother [45].

Vulnerable groups may have poorer access to information, communication technologies and face important shortcomings due to their overall literacy levels or general language barriers. Consequently, they often have a reduced capacity to navigate complex modern health care systems, understand vital health and health care information and to make the best choices for themselves and their families on health care services, but also on healthy lifestyles more generally [46]. The term "health literacy" has been coined for the complex concerns that this has raised.

Social marketing has been shown to be an effective tool for delivering health literacy to raise awareness about specific issues such as stigmatization and discrimination and provide health information about the existence and relative advantages of health interventions/services, addressing issues of price, access and environmental support [46].

\section{Organizational barriers to access}

\section{Administrative barriers}

Administrative barriers may be important reasons why some people do not get the health care they need in a timely fashion [24]. This may be due to lack of understanding of administrative procedures and requirements, which can be compounded by language barriers and the general low literacy level among the population of the Arab region. There is a need in some countries to facilitate administrative arrangements and make them more user friendly [24]. In Lebanon, for instance, the Ministry of Health covers hospitalization for any Lebanese citizen who is not already covered by one of the public providers. However, many citizens are not aware of this privilege and continue to pay out-of-pocket. This is evident in the total number of hospitalization episodes covered by the Ministry given the number of uninsured citizens [47].

\section{Organizational barriers}

Organizational arrangements can influence access to and use of services. This can be considered as a deficit in the "responsiveness" of health care services. Organizational barriers include waits and delays in accessing services at various care outlets [44]. Waiting lines are often intentional and serve to limit access when a financial barrier does not exist. This effect is most visible in the demand for elective procedures. Other examples of organizational barriers include inadequate opening hour and lack of an appointment system [24]. These barriers often serve to encourage a move to the private sector for the population that can afford it. Organizational barriers have also encouraged inpatient utilization and favoured it over ambulatory care in order to bypass such restrictions and discomfort [44]. In Kuwait, for example, the use of the emergency facilities is preferred to ambulatory centres because of the limited opening hours in health centres [48].

\section{Concentration of services}

It has been recognized that the quality of care improves with the increased volume of patients, especially for complex treatments. The quality of care provided in regionalized or centralized services is deemed higher than if they were dispersed. Decentralization has been promoted as one of the measures to improve care, facilitate access and empower communities [49].

\section{Supply-side responsiveness}

\section{Responsiveness}

The World Health Organization (WHO) defines responsiveness as all "aspects related to the way individuals are treated and the environment in which they are treated" [44]. This definition emphasizes the importance of non-health factors and their potential influence on care. Responsiveness "has the potential to reduce the threshold for seeking medical help and thus increase the likelihood of early intervention and improved compliance" [50]. The WHO definition also emphasizes that "responsiveness is related more to some of the interpersonal dimensions of quality of care rather than to technical quality". Some of the most pressing responsiveness issues relate to the level of responsiveness to gender needs.

\section{Providers}

One of the main challenges facing responsiveness relates to the interaction between doctors and patients and more specifically to the quality of their communication. It is interesting to notice that older people tend to give more favourable ratings than younger people in the evaluation of provider responsiveness [44]. Aspects such as interpersonal communication, information exchange and facilitation of patient involvement 
in decision-making can have a positive impact on patient health outcomes [36].

\section{Information technologies}

Information and communication technologies are becoming progressively more important in helping countries to improve standards of health care provision. One example relates to the use of teleradiology and telemedicine. This technology provides for technical support to providers especially in rural areas that lack specialist care, and encourage physicians to seek a second opinion from colleagues and peers.

\section{Financial barriers to access}

Private expenditure plays an important role in funding health care in the Arab region. Out-of-pocket expenditure includes payment of insurance premiums, payment for private physicians, costsharing for inpatient episodes, minimal fees for ambulatory care in the public sector, payment for over-the-counter goods and most importantly informal payments to providers and hospitals. Out-of-pocket expenditures are also required for a range of goods and services, including prescription drugs in the ambulatory settings, dental services (including dental prostheses), physiotherapy, hearing aids and glasses. Over the last 2 decades, private health care expenditure in the region has increased as a share of total expenditure on health, due to the increasing trends for privatization in several countries (Table 1).

In most countries of the region, informal payments are an important issue. Families may have to co-pay to cover part of the cost of services, hygiene materials and medicines. Patients are often obliged to reward professionals such as physicians, nurses and physiotherapists with informal payments.

Private funding of health care is often regressive and negatively impacts on the uptake of needed services. However, out-of-pocket expenditures are not only related to the absolute amount of cost-sharing. They also represent a cash flow problem since payments are often up front. In some cases, the overall caps on maximum cost-sharing are too high to effectively protect vulnerable groups [51]. Lower income groups are disproportionately affected by the financial burden of health care cost. Policy-makers have tried to address this through social benefits, such as social assistance, or shifting cost to other programmes [51].

Clients have often resorted to join a collective arrangement, such as the mutuelles in Lebanon and communitybased financing in other countries [51]. The collective usually negotiates a total package for patients. This can lead to broader coverage as the collectively arranged packages may include services that would normally be part of complementary packages.

\section{Summary}

Over the past few decades, Arab countries have witnessed marked improvements in the health status of their population, as evidenced by economic, social and health indicators [52]. Unfortunately, this improvement has not been uniform across different socioeconomic groups. Sharp social inequalities and health inequities are found between rural and urban regions, income groups, gender and ethnic groups. It is striking to see that in these countries, postnatal mortality may be 5 times greater in children belonging to the poorest quintile, as compared to children in the richest quintile. Similarly, a child of an illiterate woman is 3 times more likely to die than a child of a woman with secondary or higher level of education, and finally, postnatal mortality is 2.5 times greater in rural areas than in cities [19]. The WHO Commission on Social Determinants of Health highlighted the crucial importance of social determinants

\begin{tabular}{lcc}
\hline $\begin{array}{l}\text { Table } 1 \text { Out-of-pocket expenditure as percentage of total health expenditure in } \\
\text { Arab countries of the Eastern Mediterranean Region }\end{array}$ & $\begin{array}{c}\text { Out-of-pocket expenditure } \\
\text { as } \% \text { of total health } \\
\text { expenditure }\end{array}$ & $\begin{array}{c}\text { Total per capita health } \\
\text { expenditure } \\
\text { (US\$) }\end{array}$ \\
\hline Country & 60 & 10 \\
Sudan & 58 & 700 \\
Lebanon & 57 & 50 \\
Egypt & 56 & 15 \\
Yemen & 50 & 30 \\
Syrian AR & 50 & 60 \\
Morocco & 48 & 100 \\
Tunisia & 40 & 200 \\
Jordan & 30 & 20 \\
Djibouti & 30 & 30 \\
Iraq & 22 & 690 \\
Bahrain & 22 & 680 \\
Kuwait & 20 & 780 \\
UAE & 19 & 220 \\
Libya & 18 & 1250 \\
Qatar & 10 & 300 \\
Oman & 5 & 500 \\
Saudi Arabia & &
\end{tabular}

Source [54].

$A R=$ Arab Republic $; U A E=$ United Arab Emirates. 
in its impact on access, utilization and health status [53].

In the social field, there has been an almost total absence of sound and long-term social policies to combat poverty, deprivation, gender differences, social exclusion and unemployment. This has contributed to increased disparities within and between countries. Governments will need to address social policies to protect equity, promote solidarity and reduce inequalities.

\section{References}

1. Ensor T, Cooper S. Overcoming barriers to health service access and influencing the demand side through purchasing. Washington DC, World Bank, 2004.

2. Kronfol NM. Historical development of health professions' education in the Arab world: a review. Eastern Mediterranean Health Journal, 2012, 18:1157-1165.

3. Kronfol NM. Historical development of health systems in the Arab countries: a review. Eastern Mediterranean Health Journal, 2012, 18:1151-1156.

4. Kronfol NM. Delivery of health services in Arab countries: a review. Eastern Mediterranean Health Journal, 2012, 18:12281238.

5. Kronfol NM. Health services to groups with special needs in the Arab world: a review. Eastern Mediterranean Health Journal, 2012, 18:1247-1253.

6. Rodríguez-Sanz M, Carrillo Santisteve P, Borrell C. Desigualdades sociales en la salud, los estilos de vida y la utilización de servicios sanitarios en las comunidades autónomas 1993-2003 [Social inequalities in health, lifestyles and use of health services in the regions 1993-2003]. Madrid, Observatorio de Salud de la Mujer, 2006 (http://www.msc.es/organizacion/ sns/planCalidadSNS/pdf/equidad/Desigualdades_sociales_ salud_y_SS.pdf, accessed 6 October 2012).

7. Quality in and equality of access to healthcare services. Brussels, European Commission, Directorate-General for Employment, Social Affairs and Equal Opportunities, 2008.

8. Borrel $\mathrm{C}$ et al. Social class inequalities in the use of and access to health services in Catalonia, Spain. International Journal for Quality in Health Care, 2001, 13:117-125.

9. Borrell C. Desigualdades y servicios de salud [Inequalities and health services.] Saúde e Sociedade, 2006, 15:9-22.

10. Palanca Sánchez I. Desigualdades en salud y exclusión social [Health inequalities and social exclusion]. Revista Bimestral de la Fundación Secretariado General Gitano, 2002, 15.

11. Oral health: action plan for promotion and integrated disease prevention. Executive Board, 120th session. Resolution adopted at the sixtieth World Health Assembly, Geneva, World Health Organization, 2007 (EB120.R5).

12. Huber $M$ et al. Quality in and equality of access to health care services. Brussels, European Commission, Directorate-General for Employment, Social Affairs and Equal Opportunities, 2008.

13. Foster J et al. A qualitative study of older people's views of out-of-hours services. British Journal of General Practice, 2001, 51:719-723.

14. Stark $\mathrm{C}$ et al. The effect of access factors on breast screening attendance on two Scottish islands. Health Bulletin, 1997, 55:316-321.

15. Goddard M, Smith P. Equity of access to health care. York, England, University of York Centre for Health Economics, 1998 (Working Paper No. 32).

16. Dixon-Woods $M$ et al. Vulnerable groups and access to health care: a critical interpretive review. Report for the National Coordinating Centre for NHS Service Delivery and Organisation $R$ $\& D$. London, National Coordinating Centre for NHS Service Delivery and Organisation, 2005.
17. Haynes R. Chapter 2. Geographical access to health care. In: Gulliford M, Morgan M, eds. Access to health care. London, Routledge, 2003:13-35.

18. INTRA project Lebanon. World Health Organization [online] (http://www.who.int/ageing/projects/intra/phase_one/alc_ intra1_finalreport_lebanon.pdf, accessed 6 October 2012).

19. Boutayeb A, Helmert U. Social inequalities, regional disparities and health inequity in North African countries. International Journal for Equity in Health, 2011, 10:23.

20. Kronfol N. Beyond reconstruction: a national strategy for health system development in Lebanon. Beirut, Ministry of Health Lebanon, World Bank and World Health Organization, 2006.

21. Boutayeb A, Serghini M. Heath indicators and human development in the Arab region. International Journal of Health Geographics, 2006, 5:61.

22. Ibnouf $\mathrm{AH}$, van den Borne HW, Maarse JA. Utilization of antenatal care services by Sudanese women in their reproductive age. Saudi Medical Journal, 2007, 28:737-743.

23. DeCola PR. Gender effects on health and healthcare. Social and biological determinants in health and disease. In: Schenck-Gustafsson K, et al., eds. Handbook of clinical gender medicine. Basel, Karger, 2012:10-17.

24. Goddard MK. Quality in and equality of access to healthcare services. Country report for England. York, England, University of York Centre for Health Economics, 2008.

25. Sen G, Östlin P. Unequal, unfair, ineffective and inefficient-gender inequity in health: why it exists and how we can change it. Final report to the WHO Commission on Social Determinants of Health. Stockholm, Karolinska Institutet, Women and Gender Equity Knowledge Network, 2007.

26. About UN Women. United Nations Entity for Gender Equality and the Empowerment of Women [website] http://www. unwomen.org/about-us/about-un-women/; accessed 6 October 2012).

27. Gijsbers van Wijk CM, van Vliet KP, Kolk AM. Gender perspectives and quality of care: towards appropriate and adequate health care for women. Social Science and Medicine, 1996, 43:707-720.

28. Noureddine $\mathrm{S}$ et al. Response to signs and symptoms of acute coronary syndrome: differences between Lebanese men and women. American Journal of Critical Care, 2008, 17:26-35.

29. O'Keefe-McCarthy S. Women's experiences of cardiac pain: a review of the literature. Canadian Journal of Cardiovascular Nursing, 2008, 18:18-25.

30. Kamel MI et al. Gender differences in health care utilization and outcome of respiratory tuberculosis in Alexandria. Eastern Mediterranean Health Journal, 2003, 9:741-756.

31. Bashour H, Mamaree F. Gender differences and tuberculosis in the Syrian Arab Republic: patients' attitudes, compliance and outcomes. Eastern Mediterranean Health Journal, 2003, 9:757-768.

32. Goddard M, Smith P. Equity and access to health care services: theory and evidence from the UK. Social Science and Medicine, 2001, 53:1149-1162. 
33. Dixon-Woods $M$ et al. Vulnerable groups and access to health care: a critical interpretive review. Report for the National Coordinating Centre for NHS Service Delivery and Organisation R $\& D$. London, National Coordinating Centre for NHS Service Delivery and Organisation, 2005.

34. Elnekave E, Gross R. The healthcare experiences of Arab Israeli women in a reformed healthcare system. Health Policy, 2004 69:101-116.

35. Atkinson, M. et al. Systematic review of ethnicity and health service access for London. Warwick, University of Warwick Press, 2001.

36. Cooper L, Roter D. Patient-provider communication: the effect of race and ethnicity on process and outcomes of healthcare. In: Smedley B, Stith A, Nelson A, eds. Unequal treatment: confronting racial and ethnic disparities in health care. Washington DC, National Academies Press, 2003:552-593.

37. Hull S, Boomla K. Primary care for refugees and asylum seekers. British Medical Journal, 2006, 332:62-63.

38. The Bedouin Health Project: findings indicate high levels of discrimination and difficult access to health services. CRPH News, No. 8, December 2008 (http://www.aub.edu.lb/fhs/crph/ publications/Documents/CRPHNews8_1208.pdfaccessed 6 October 2012)

39. Elnekave E, Gross R. The healthcare experiences of Arab Israeli women in a reformed healthcare system. Health Policy, 2004, 69:101-116.

40. Shah NM, Shah MA, Behbehani J. Ethnicity, nationality and health care accessibility in Kuwait: a study of hospital emergency room users. Health Policy and Planning, 1996, 11:319-328.

41. Ben Romdhane H, Grenier FR. Social determinants of health in Tunisia: the case analysis of Ariana. International Journal for Equity in Health, 2009, 8:9.

42. Hessini L. Abortion and Islam: policies and practice in the Middle East and North Africa. Reproductive Health Matters, 2007, 15:75-84.

43. El-Sherbini AF et al. Assessment of knowledge, attitudes and practices of expectant mothers in relation to antenatal care in Assiut governorate. Journal of the Egyptian Public Health Association, 1993, 68:539-565.
44. Valentine $\mathrm{N}$ et al. Health system responsiveness: Concepts, domains and operationalization. In Murray C, Evans D, eds. Health system performance assessment: debates, methods and empiricism. Geneva, World Health Organization, 2003.

45. Kishk NA. Knowledge, attitudes and practices of women towards antenatal care: rural-urban comparison. Journal of the Egyptian Public Health Association, 2002, 77:479-498.

46. About Healthy People. Healthy People 2020 [website] (http:// www.healthypeople.gov/2020/about/default.aspx, accessed 6 October 2012)

47. Ammar W. Health beyond politics. Beirut, Lebanon, World Health Organization Country Office, 2009.

48. Al-Hay AA, Boresli M, Shaltout AA. The utilization of a paediatric emergency room in a general hospital in Kuwait. Annals of Tropical Paediatrics, 1997, 17:387-395.

49. Decentralization and health system reform. Bethesda, Partner for Health Reform Plus, 2002

50. Bramesfeld A et al. How do patients expect the mental health service system to act? Testing the WHO responsiveness concept for its appropriateness in mental health care. Social Science and Medicine, 2007, 65:880-889.

51. The impact of health expenditure on households and options for alternative financing. Technical paper presented at the fifty-first session of the Regional Committee for the Eastern Mediterranean. Agenda item 6(a). Cairo, World Health Organization Regional Office for the Eastern Mediterranean, 2004 (EM/ RC51/4).

52. International Human Development Indicators. United Nations Development Programme [online database] (http://hdrstats. undp.org/, accessed 6 October 2012).

53. WHO Commission On Social Determinants of Health. Closing the gap in a generation: health equity through action on the social determinants of health. Geneva, World Health Organization, 2008.

54. Abdullatif AA. Aspiring to build health services and systems led by primary health care in the Eastern Mediterranean Region. Eastern Mediterranean Health Journal, 2008, 14(Suppl.):S23. 